\title{
Camino sin camino \\ Una reflexión filosófica actual desde la mística de Eckhart y Silesius
}

\author{
CARlos ARTURO ARIAS SANABRIA \\ Pontificia Universidad Javeriana (Colombia) \\ carlos-arias@javeriana.edu.co
}

\section{Resumen}

El objetivo del presente artículo es múltiple. Primero, pondera una serie de razones por las cuales la mística aún es relevante para el análisis de la condición humana del hombre actual. Segundo, propone a la promesa y a la ausencia como dispositivos de la mística. Tercero, expone, desde la lectura que hacen Alois Haas y Amador Vega de algunos sermones alemanes del Maestro Eckhart y de El peregrino querúbico de Angelus Silesius, los planteamientos fundamentales de la mística de estos autores, a saber: el vaciamiento del alma, el coengendramiento, el abismo de Dios y la unión mística. Al mismo tiempo esboza cómo el pensamiento de Eckhart y Silesius, además de ser estudiado, produce ecos en algunas de las formulaciones filosóficas más importantes del siglo XX.

Palabras clave: desasimiento, alma, vacío, abismo, camino.

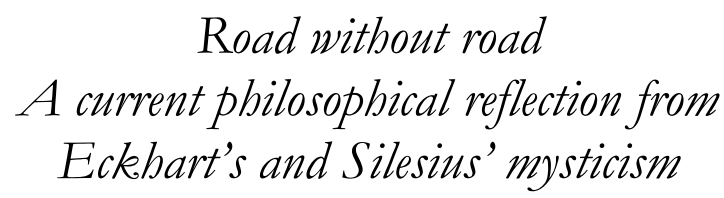

Abstract

The aim of this article is multiple. First, it weighs a series of reasons for which mysticism is still relevant for the analysis of man's current human condition. Second, it proposes promise and absence as the devices of mysticism. Third, it exhibits, according to the reading of Alois Haas and Amador Vega of some of Meister Eckhart's German sermons and Angelus Silesius' The Cherubic W anderer, the fundamental expositions of these authors' mysticism, namely: voidance of the soul, co-conceivement, God's abyss and mystical union. At the same time it outlines how the thought of Eckhart and Silesius, besides being studied, produces echoes in some of the most important philosophical formulations of the 20th century.

Key words: detachment, soul, empty, depths, road.

Magister en Estudios Comparados de Literatura, Arte y Pensamiento (Universitat Pompeu Fabra, España) y Licenciado en Filosofía (Pontificia Universidad Javeriana, Colombia). Asistente editorial de la revista de filosofía Universitas Philosophica, investigador del grupo Biblioteca Virtual del Pensamiento Filosófico en Colombia (BVPFC) y Profesor de la Facultad de Filosofía de la Pontificia Universidad Javeriana, Bogotá. 


\section{Introducción}

A partir del pensamiento místico del Maestro Eckhart y de Angelus Silesius, expuestos en los sermones del primero y en la obra El peregrino querúbico del segundo, nos proponemos mostrar la actualidad y la relevancia de sus postulados para la reflexión filosófica contemporánea. Para ello, de la mano de las interpretaciones de pensadores de los siglos XX y XXI recorreremos el trayecto propuesto en este artículo en cuatro estaciones. La primera tiene como objetivo bordear el concepto de mística que se desarrolla en el artículo, por un lado, y demarcar la relevancia de la mística para el análisis de la condición humana del hombre actual, por otro lado. Para tal fin, abordaremos la tematización religiosa del hombre, el modus loquendi propio de la mística y, la promesa y la ausencia como dispositivos del reflexionar místico actual. En la segunda estación recorreremos el camino sin camino gracias al cual se exponen, siguiendo los análisis de Alios Hass y Amador Vega, los planteamientos fundamentales de la mística del Maestro Eckhart y de Angelus Silesius, los cuales resuenan como ecos fértiles en algunos de los postulados filosóficos más importantes del siglo XX, como los de Heidegger, Arendt y Derrida. La tercera estación de este recorrido, partiendo de los insumos de la anterior, trata de delinear una ética mística de la vida cotidiana en la que es necesario actuar con orden, inteligencia y prudencia. Finalmente, como un gozne, la cuarta parada de este trayecto nos remitirá a la dinámica doble de salida y entrada y, entrada y salida mística, que consiste en salir del yo creatural que está en el mundo para entrar en el yo espiritual; y después, en un salir de ese yo espiritual, pero sin abandonarlo, para entrar nuevamente en el yo creatural, que no es el mismo de antes porque ahora está junto al mundo.

\section{Consideraciones preliminares}

De esta manera, nos referimos a un camino recto o curvilíneo, hacia arriba, abajo, derecha, izquierda, en diagonal, en zigzag, etc., que da la impresión de tener un punto de inicio y uno de llegada, es decir, que el caminante conoce el momento en que da el primer y el último paso. Sin embargo, la vida, ese trasegar de todos los días, es un caminar impuesto al hombre tanto en su inicio como en su final, pues esos dos momentos, el nacimiento y la muerte -más allá de la manipulación biogenética o de cualquier decisión paterna o médica, y también del asesinato o del suicidio- se escapan a cualquier administración humana. Por esta razón, el ser humano configura «una tematización religiosa de una experiencia existencial absolutamente irreprimible (...) a saber, de la experiencia de nues- 
tra absoluta dependencia respecto de condiciones existenciales de las que la existencia misma no puede disponer» (Lübbe Hermann citado en Haas, 2007: 13-15) ${ }^{1}$.

La tematización religiosa llevada a cabo por el hombre ante su sentimiento de dependencia se puede configurar, ora desde la religión, ora desde la espiritualidad ${ }^{2}$, ora desde la mística ${ }^{3}$. Y puesto que estos tres fenómenos no son equiparables entre sí, tomaremos el camino de la mística ya que ésta, además de ser «entendida como la tendencia fundamental de la existencia humana hacia la unidad con el fundamento desde y hacia el cual transcurre la vida» (Haas, 2007: 21), es un fenómeno de carácter universal que trasciende el marco de lo netamente religioso. Así, si tomamos esta vía de tematización no queda duda de que, tal como lo manifestara Alois M. Haas en la conferencia inaugural de la Bibliotheca Mystica et Philosophica Alois Maria Haas de la Universitat Pompeu Fabra, la mística es aún hoy un aspecto importante, y según parece lo seguirá siendo, para la comprensión de la existencia humana (Haas, 2007: 11).

Que esa postura sea sostenida en el siglo XXI no deja de ser paradójico, pues estamos, según nos dice Haas, en un mundo en el que a causa de la saturación informativa, tanto de imágenes como de lenguaje, parece

1 En términos schopenhauerianos, la tematización religiosa es la necesidad metafísica del hombre que se origina por el asombro de su propia existencia. Se trata de «un asombro producido por el mundo y nuestro propio existir, que siempre se impone al intelecto como un enigma cuya solución ha ocupado a la humanidad permanentemente» (Shopenhauer, 2010: 224, 188). Y continúa el filósofo: «Sólo al animal carente de pensamiento le parece el mundo y la existencia comprensibles de suyo: en cambio para el hombre esto es un problema, del que se da cuenta vivazmente incluso el más inculto y limitado en los momentos de lucidez, pero que aparece con tanta mayor claridad en la consciencia cuanto más reflexivo sea uno y más material para pensar le haya procurado la formación, hasta que finalmente en las cabezas inclinadas al filosofar se eleva ese «asombro tan propio del ánimo filosófico», esa admiración que abarca en su conjunto el problema que ocupa constantemente a la humanidad más noble de cada época y cada país causándole una continua desazón» (Shopenhauer, 2010: 225-226, 189).

2 La espiritualidad es, de un lado, según Alois Haas (1999), un concepto que se ha degradado hasta el punto que solo dice lo que de él se interpreta ya que es aplicable a todo, por lo que es necesario definirlo. De otro lado, según los postulados de Michel de Certeau en la relación entre cultura y espiritualidad, toda espiritualidad tiene un carácter primordialmente histórico, ya que «responde a los interrogantes de un tiempo, y nunca les responde de otra manera que en los mismos términos de tales interrogantes, porque son aquellos que viven y que hablan los hombres de una sociedad; tanto los cristianos como los otros. (...) tiende a manifestar cómo vivir lo Absoluto en las condiciones reales fijadas por una situación cultural» (De Certeau, 2006a: 51).

Sin la intensión de ofrecer una definición de lo que es la mística, seguimos a Alois Haas (1999: 99) cuando se refiere a esta ciencia como: «sobre todo junto al aspecto experiencial que con razón presenta, una penetración inquierente, apremiante y reflexiva en los misterios de la unión del hombre con Dios». 
no haber teofanías; en un mundo en el que el hombre advierte, en medio de su búsqueda por expresar lo vitalmente necesario -su dependencia existencial-, "que también aquí -en el mundo- se topa con una carencia fundamental, esto es, con la falta de visibilidad de Dios. Dios es un Dios oculto» (Haas, 1999: 92-93). Justo por esta falta de presencia de Dios en el mundo, el hombre creyente, siempre en búsqueda de la huella de Dios, se concibe verbalmente incapacitado en lo que respecta a la trascenden$\mathrm{cia}^{4}$. Sin embargo, más allá de la insuficiencia comunicacional de las señales verbales o no verbales del hombre, hay una fuente de valor indudable que permite reflexionar la existencia humana desde la perspectiva mística, a saber: los textos catalogados como tales. En estos se muestra una particular manera de hablar, un modus loquendi místico con sus tensiones, limitaciones y excesos lingüísticos en el intento por decir algo acerca de lo inefable, que:

por definición, (...) apenas puede ser expresión de una lógica cualquiera: lo que no puede decirse se sustrae a su denominación lingüística y por tanto también a todo logos en el sentido amplio de la palabra. La consecuencia para el habla humana es clara: lo inefable trasgrede las dimensiones de una lógica fraseológica predeterminada y quizá sólo alcanza una resolución lingüística en el contexto de especiales manipulaciones retóricas (Haas, 2009: 19).

Los libros místicos, entonces, no dejan de construir una realidad histórica en la que, como señaló Michel de Certeau en La fábula mística, «el discurso místico transforma el detalle en mito; se apega a él, lo desorbita, multiplica y diviniza. Hace de él su historicidad propia» (2006b: 19). Esto es, en otras palabras, la búsqueda de la mística por encontrar un lugar propio de enunciación desde el cual dejar fluir su pasión por lo que es, por el mundo tal como acaece. Esto nos lleva a recordar las palabras de Wittgenstein en la proposición 6.44 del Tractatatus Logico-Philosophicus: «No cómo sea el mundo es lo místico sino qué sea» (Wittgenstein, 1999: 181). Así, se hace patente la lucha constante que tienen los místicos con el lenguaje en cuanto a sus maneras de hablar, por lo que se ven obliga-

4 Para el filósofo y teólogo canadiense Bernard Lonergan, gran parte de la incapacidad humana acerca de la trascendencia es causada, además de la insuficiencia de la comunicación del hombre, por el desconocimiento, en términos epistemológicos, de la trascendencia. Por esta razón, para Lonergan la trascendencia significa un desarrollo del conocimiento humano que es pertinente para el progreso del propio hombre en el ser, de tal manera que «el ámbito trascendente puede ser concebido o bien de manera relativa o bien de manera absoluta, o bien como lo que está más allá del ser humano o bien como lo último en el proceso íntegro de ir más allá» (Lonergan, 1999: 732). Para un desarrollo más detallado de esta postura, véase: Lonergan (1999: 731-835; 2006). 
dos a fabricar palabras, frases y giros lingüísticos en una región en la que oyen una voz que nunca termina de empezar.

En definitiva, de lo que se trata en los textos místicos no es tanto de un tema sino de la novedad lingüística, el modus loquendi en que se expresa lo inefable y la unión del hombre con Dios. Es decir que lo esencial de la mística es, de un lado, el movimiento por el que el sujeto es desplazado al campo del discurso místico, en el que se señala el nuevo uso que se les da a las palabras; de otro, el giro lingüístico que ubica al yo en el lugar de enunciación de los textos místicos. De este modo, si la pregunta reguladora del discurso fuera: ¿Quién habla y desde dónde? La respuesta sería: el místico que se sitúa en el acto enunciativo. Su yo toma el lugar infinito del narrador puesto que el yo místico no puede sino ocupar el lugar de quien habla o a quien se habla, esto es, es narrador u oyente.

Por tanto, tal como lo manifiesta Michel de Certeau, en la mística «la estrategia textual que distribuye y jerarquiza los lugares del decir (los apóstoles, el autor, los destinatarios, etc.) desemboca finalmente en este punto de fuga, el yo, donde eso no habla si no es en nombre de otro» (De Certeau, 2006b: 187). Así, el inicio de la experiencia mística, tomada desde sus textos, es la actividad por la cual el discurso se posiciona para tematizar la visión o contemplación de Dios. En palabras de Alois Haas, la mística «ocupa el lugar de un "punto culminante de la vida anímica" y, con ello, adquiere el rango de tema infinito en el intercambio lingüístico general entre los humanos» (Haas, 2007: 29).

Entonces, el modus loquendi de la mística es caracterizado como un género literario, como un estilo, puesto que a él pertenece un lenguaje y un lugar propio de enunciación desde el que se restaura el espacio social como condición del decir. Por ello el proyecto místico medieval pasa por unificar el conocimiento en un nuevo lenguaje, creado por cortes de la palabra a la lengua materna, pues se «significa mediante lo que se elimina» (De Certeau, 2006b: 139). Estos cortes de sentido en el lenguaje, propios del estilo de Juan de la Cruz, que simbolizan el sacrificio y la alianza, la unión con Dios, nos remiten a la dimensión misteriosa de la existencia en la que la mística, en cuanto modo de transgresión existencialtrascendental, sigue siendo importante para la compresión de la naturaleza humana. Como sostiene Haas en Visión en azul, «la mística es, sobre todo junto al aspecto experiencial que con la razón presenta, una penetración inquiriente, apremiante y reflexiva en los misterios de la unión del hombre con Dios» (Haas, 1999: 99). En último término, es un movimiento irracional, lo que no significa indistinto y sin sometimiento a la razón, sino la sustitución de una razón lógica por una paradójica (Vega, 2011: 46), un acontecimiento que por su profundidad se escapa a toda interpretación comprensiva de Dios como promesa. 
Como toda promesa, Dios es, siguiendo el planteamiento de Jacques Derrida, un horizonte de expectativas que viniendo del pasado, ya que es previo a cualquier acto enunciativo, se despliega hacia el futuro. De esta manera, la palabra dada -el logos, el verbo donado- permanece en el tiempo desde antes del acto de prometer hasta el cumplimiento de la promesa, si es que lo hay (si c'est qu'ily a), pues hemos de ser conscientes del fracaso de la promesa. Por ello, dado que «el discurso sobre la promesa es por adelantado una promesa: en la promesa» (Derrida, 2011a: 22), hablar de la ella no es algo que se pueda prometer estando fuera, sino sólo desde su interior, pues todo intento de tomar un punto de enunciación desde un lugar metaligüístico o metapromisorio sería un ensayo por estar en «la posición a la vez más ventajosa y más difícil de encontrar, la más absurda y la más insostenible, la menos justa en cualquier caso» (Derrida, 2002: 251). La presencia que se expresa en el en de la promesa acompaña la travesía de la teología negativa en la que se atrapa al yo que promete, pero de ningún modo se limita por la preposición en la que se manifiesta. Así, como hay presencia en lo que se dice, es decir, hay acontecimiento en el habla y en la escritura, se produce el momento afirmativo del no de la teología apofática ${ }^{5}$, que también debe ser dicho.

Al ubicarnos en el momento afirmativo de la teología negativa estamos pisando el campo de la mística de beguinas de Hadewijch de Amberes, Margarita Porete y Matilde von Magdeburg ${ }^{6}$, y de la mística especulativa de procedencia neoplatónica del Maestro Eckhart en los siglos XIII y XIV, así como la de Angelus Silesius en el siglo XVII, para quienes la unión del hombre con Dios es pensada de un modo tan radicalmente trascendente que ni el conocimiento ni el amor pueden tener una función capaz de ser nombradas (Haas, 1999: 98). Por ello, el discurso propio de la teología apofática, y por tanto también de la mística especulativa, es un modo de predicar sobre Dios en el que «esto, que se llama X (...) "no es" ni esto ni aquello, ni sensible ni inteligible, ni positivo ni negativo, ni

5 En junio de 1986, Derrida abrió el coloquio Ausencia y negatividad, organizado por The Hebrew University y The Insititute for Advanced Studies de Jerusalén, con la conferencia How to avoid speaking en la que hace una exposición de la teología negativa desde la lectura de textos de Dionisio de Aeropagita y del Maestro Eckhart. El filósofo de origen argelino sostiene que, «bajo el título muy laxo de "teología negativa", se designa frecuentemente (...) una cierta forma de lenguaje, con su puesta en escena, sus modos retóricos, gramaticales, lógicos, sus procedimientos demostrativos, en una palabra, una práctica textual atestiguada, o situada "en la historia"» (Derrida, 2011a: 13). A partir de esta noción general de teología apofática, Derrida expondrá, a lo largo de su conferencia, cómo el movimiento de la negatividad genera cierta positividad.

6 Para profundizar sobre la postura de las místicas de Beguinas, véase: De Amberes (2013) y (2005); Porete (2008); Von Magdeburg (2004). 
dentro ni fuera, ni superior ni inferior, ni activo ni pasivo, ni presente ni ausente, ni siquiera neutro, ni siquiera dialectizable en un tercero, sin relevo (Aufhebung) posible, etc.» (Derrida, 2011a: 14).

Dado que esa $\mathrm{X}$ excede la estructura del discurso predicativo - porque ni es ni dice lo que es- exige otra sintaxis, un nuevo modus loquendi. De lo anterior no se sigue que no haya un discurso posible sobre lo inefable y sobre la unión del hombre con Dios, sino que, por el contrario, en la teología apofática basta con llevar hasta el límite la negatividad para hacer alusión a Dios. Como sostiene Derrida, «si hay un trabajo de la negatividad en el discurso y en la predicación, ese trabajo produciría la divinidad» (Derrida, 2011a: 15). Por tanto, el lado positivo del no es la referencia indirecta y negativa a Dios, pues así éste se ubica como el origen y el final de todo trabajo sobre lo negativo, de modo que «Dios sería la verdad de toda negatividad» (Derrida, 2011a: 15). Y el filósofo francés, usando la conocida expresión de Dionisio, continúa: “"Dios” nombraría aquello sin lo cual no se podría dar cuenta de ninguna negatividad: la negación gramatical, la enfermedad, el mal, la neurosis finalmente» (Derrida, 2011a: 15-16).

De otro lado, tal como señala Michel de Certeau al inicio de La fábula mística, Dios también es ausencia ${ }^{7}$, con lo cual, nuestro estudio de la mística no puede ser otra cosa que un trabajo de duelo, contrario del proceso melancólico que llevaba a cabo el místico del siglo XVI o XVII, quien intentaba reencontrar la presencia del Hijo encarnado que ya no está, que «se lo han llevado» (Jn 20,2). Al respecto, en Duelo y melancolía Sigmund Freud (2003) sostiene que si bien las coincidencias en los cuadros generales del duelo (la reacción a la pérdida de un ser amado o de una abstracción equivalente: la patria, la libertad, el ideal, etc.) y la melancolía (estado de ánimo profundamente doloroso, una cesación del interés por el mundo exterior, la pérdida de la capacidad de amar, la inhibición de todas las funciones y la disminución de amor propio) son numerosas, de tal manera que es posible plantear un paralelo entre ambos estados; éstos se diferencian porque mientras que al final del proceso de duelo el yo puede quedar libre y exento de toda inhibición debido a que entiende

Tal como lo manifestó Lluís Duch en el evento de lanzamiento de Tres poetas del exceso. La hermenéutica imposible en Eckhart, Silesius y Celan, de Amador Vega, el 04 de octubre de 2011 en la librería La Central, de Barcelona, «el místico encuentra una perplejidad para decantar entre el significado y los significantes, entre los artefactos gramaticales y lo que estos artefactos significan. Se encuentra siempre con la necesidad de representar. De ahí la lucha constante que mantiene el místico entre representación y presencia. Intenta alcanzar la presencia pero sólo puede hacerlo a partir de representaciones. Y en el fondo, de hecho, toda representación es una confirmación de ausencias, de vacíos, de falta». 
que el objeto amado ha sido sustraído, en la melancolía la pérdida de dicho objeto no es real sino ideal, de tal manera que, como el objeto de deseo no ha muerto, el sujeto no es consciente de todo lo que implica la pérdida del mismo, por lo cual el yo no se libera. Por ello, la pérdida melancólica es conocida al enfermo, quien sabe a quién ha perdido, pero no lo que con él ha perdido. De esta manera, la pérdida de la melancolía, a diferencia del duelo, en el que nada es inconsciente, es la pérdida del objeto sustraída a la conciencia (Freud, 2003: 2092). Siguiendo el planteamiento de Ricardo Nava Murcia (2011: 46):

la noción de 'trabajo de duelo' se sostiene en el hecho de que, quien está en duelo debe llevar a cabo un trabajo, esto es, seguir ciertos pasos que lo lleven a dejar de desear lo ausente interiorizándolo y asimilándolo como objeto del deseo. De esta manera el objeto perdido viene a ser sustituible. El sujeto sólo cambia el estatus del objeto a partir de sustituirlo por otro. Es en ese momento que se efectúa un buen trabajo de duelo que lleva, al que está de duelo, a superar la pérdida y le evita caer en estados de melancolía ${ }^{8}$.

De ahí que el jesuita francés base su trabajo reflexivo en la otredad que nos falta y nos funda y que tiene sus raíces en la reflexión mística, pues ésta es una búsqueda marcada por la herida de la ausencia del otro que no regresará. En palabras del Michel de Certeau: «Lo que debería estar aquí no está: sin ruido, casi sin dolor, esta constatación está presente» (De Certeau, 2006b: 11). Entonces, la mística es la búsqueda de algo que se ha perdido, y desde la que se articula un nuevo espacio del saber. Una manera diferente de practicar el lenguaje recibido se objetiva en un conjunto de limitaciones y de procesos de búsqueda.

Por esa búsqueda «es místico aquel o aquella que no puede parar de caminar y que, con la certidumbre de lo que le falta, sabe, de cada lugar y de cada objeto, que no es eso, que uno no puede residir aquí ni contentarse con estar (De Certeau, 2006b: 294). El deseo del místico crea un exceso que lo lleva a perder los lugares, a ir más lejos, a ir a otra parte, a no habitar ningún lugar. El deseo de encontrar lo ausente es lo que hace del místico un peregrino ${ }^{9}$ que se las ha de ver con la topografía religiosa, en la

8 Para la relación entre psicoanálisis y mística, véase el libro La mística salvaje, de Michel Hulin, en el que siguiendo lo que Romain Rolland denominó «sentimiento oceánico» hace un estudio de aquellos EMC (estados modificados de conciencia -altered states of consciousness) que podrían tener un significado místico porque «el sujeto experimenta la impresión de despertarse a una realidad más elevada, de atravesar el velo de las apariencias, de vivir por anticipado algo semejante a una salvación» (Hulin, 2007: 14-15).

9 Labadie es, para Michel de Certeau, el peregrino por excelencia, pues es un «Wandersman, a la vez errante y emigrante. (...) El "nomadismo infatigable" de este 
que el abismo y el desierto, siguiendo las metáforas de Eckhart, son dos «imágenes que el alma reconocerá en su camino hacia la divinidad» (Vega, 2011: 39).

Con todo, en este apartado hemos mostrado cómo el camino místico está aún presente en nuestros días, pues en sentido lato la mística es una manera de tematizar la existencia del hombre en su relación con Dios, siempre partiendo de la condición humana. También hemos expuesto cómo la reflexión mística sobrepasa los límites del lenguaje porque ésta excede cualquier posibilidad de verbalización en la lógica humana y exige una razón paradójica. Asimismo, hemos propuesto dos dispositivos, no los únicos, que dan inicio al trasegar místico: uno, la promesa, que desde el pasado envuelve el futuro en un presente de la reflexión sobre Dios; otro, la ausencia, que como un leitmotiv de toda la mística hace que los pies de los místicos se muevan y formen camino, en búsqueda del Uno, de la unión con Dios, en donde todo camino termina siendo un no camino. En las siguientes secciones examinaremos cómo los postula-

héroe barroco hace pertinente una problemática del espacio. El viaje interior se transforma en itinerancia geográfica. La historia de Labadie es el espacio indefinido creado por la imposibilidad de un lugar» (De Certeau, 2006b: 268). Esta imposibilidad locativa se ve también en la errancia mística, la cual implica no saber por anticipado el lugar al que se va, sino, simplemente, seguir con el caminar. Al respecto, en El tiempo de una tesis: puntuaciones, texto presentado por Jacques Derrida como presentación de su tesis doctoral el 2 de junio de 1980 en la Universidad la Sorbona ante el tribunal evaluador, del cual hacía parte entre otros profesores Emmanuel Lévinas, el filósofo de origen argelino trae a colación una anécdota que vivió en un congreso en Estados Unidos en el que participó junto con su primer director de tesis: Jean Hyppolite. Allí, después de que Hyppolite realizara algunos comentarios sobre la conferencia de Derrida, le dijo a éste: «Aparte eso, verdaderamente no veo adónde va usted»; sin embargo, lo más interesante de la anécdota es la respuesta de Derrida, junto con el análisis que él mismo hace de ella en 1980: «Creo haberle contestado poco más o menos lo siguiente: «Si viese claramente, y por anticipado, adónde voy, creo realmente que no daría un paso más para llegar allí». Quizás pensé entonces que saber adónde se va puede indudablemente ayudar a orientarse en el pensamiento, pero no ha hecho jamás dar un paso, todo lo contrario. ¿Para qué ir adonde se sabe que se va y adonde se sabe uno destinado a llegar? Al recordar hoy esta respuesta, no estoy seguro de comprenderla bien, pero seguramente no quería decir que nunca veo adónde voy ni que no lo sé, y que, en consecuencia, en esa medida, en la medida en que sé, no es seguro que haya dado jamás un paso, o, que haya dicho algo. Eso quiere decir también, quizás, que de ese lugar adonde voy sé lo bastante como para pensar, con un cierto terror, que allí las cosas no marchan bien, y que, teniéndolo en cuenta todo, mejor valdría no dirigirse allí. Pero hay Necesidad, una figura que he querido llamar recientemente Necesidad, con la mayúscula de un nombre propio, y Necesidad dice que siempre hay que rendirse. Con riesgo de no llegar. Con riesgo, dice, de no llegar. Liberado con que no llegues. (Quitte á ne pas arriver. Quitte, dit-elle, á ne pas arriver. Quitte pour ce que tu n'arrives pas)» (Derrida, 2011b: 13). 
dos del Maestro Eckhart, en algunos de sus sermones alemanes, y de Angelus Silesius, en su obra El peregrino querúbico, devienen camino sin camino.

\section{Camino sin camino. Del doble movimiento de Eckhart y Silesius hacia el pensamiento filosófico del s. XX}

El camino sin camino es un doble camino de negación que se puede recorrer de dos maneras, las cuales, aunque parezcan diferentes, no se excluyen entre sí: una, el amor; otra, el conocimiento. En palabras de Haas (1999: 96), «dos fuerzas son las que han empujado al hombre: el intelecto y el afecto, la facultad de pensar y la de amar». Cabe aclarar que estas dos facultades no son dos vías distintas en la búsqueda reflexiva de una experiencia mística de lo inefable, sino que las facultades del conocimiento y del amor del hombre se han de pensar, también ayudados por la historia de los movimientos espirituales occidentales, en su relación intrincada y sutil ${ }^{10}$. Por esta razón, dejando a un lado el prejuicio que califica la mística cristiana como basada en el sentimiento y el oscurantismo, intentaremos recorrer el doble camino de la mística partiendo del lado especulativo pero abiertos a toparnos constantemente, como es de suponer, con el andar del amor. Así, se trata de entender la reflexión como un doble movimiento liberador de negación (tanto del ser como del no-ser), pues, como sostiene Amador Vega (2006: 244-245):

(la reflexión) supone un primer momento de rechazo de lo que nos es exterior, al girar la mirada hacia el centro más profundo del ser (...), con la intención de tomar conciencia de nuestro lugar ante el mundo, y ante las cosas del mundo, que contribuye de forma continuada a nuestra dispersión. Pero aquí no acaba todo, ya que en un segundo movimiento, aquel espíritu, aislado ahora ya de todo, se niega de nuevo a sí mismo para retornar al mundo. La mirada sobre éste, sin embargo, ya no es la misma, puesto que la máxima apertura, que se produce como causa de la máxima oclusión sufrida por el espíritu en el ejercicio de recogimiento que requería la reflexión, se enfrenta ahora a la realidad con una libertad de acción configurada a lo largo del proceso de doble negación.

Sobre la primera parte de este doble movimiento, Eckhart afirma en su sermón El templo vacio ${ }^{11}$ que sólo es posible dirigirse hacia el interior

\footnotetext{
10 Sobre la tensión entre amor y conocimiento en el pensamiento místico, véase: McGinn (1989).

11 En el presente escrito seguiremos, en la mayoría de los casos, la traducción al castellano de los sermones de Eckhart hecha por Amador Vega, señalando la página y la
} 
del ser cuando éste se abandona y se desprende de su yo psicológico, de su ser creatural. Es decir, el movimiento hacia adentro es posible si el alma se desnuda de toda imagen o ídolo que ocupe el lugar que sólo es para Dios, pues es la única manera de que la divinidad entre en ella y la habite a su antojo, del mismo modo de que el hombre habite en la divinidad. Se trata, en últimas, de alcanzar el anonadamiento del alma renunciando a toda intención mundana y especulativa. Con esto, tal como sostiene Haas (2002: 41), "se exige del hombre una radical, casi absoluta y perfecta pobreza de espíritu, abandono y desasimiento, y, con ello, un proceso sin fin de dejar de ser, de des-devenir [entwerden]». De este modo, el alma no sólo será pura sino también fértil para el coengendramiento de Dios y del hombre. Como afirma el Maestro Eckhart (2011: 64, 88-91; 1983: 274), el alma «llega a ser fecunda coengendrando a partir del mismo fondo del que el Padre da nacimiento a su Verbo eterno». Por ello, en el sermón Vivir sin porqué el dominico muestra la dinámica del coengrendramiento a la manera de una conecesidad y de una semejanza entre Dios y el hombre, sus palabras son las siguientes: «Aquí el fondo de Dios es mi fondo, y mi fondo es el fondo de Dios. Aquí vivo de lo mío, como Dios vive de lo suyo» (Eckhart, 2011: 72, 83-85; 1983: 307).

En este fondo-fundamento (grund) se da el encuentro de Dios, abandonado de sí mismo, y del alma, también vaciada de sí. Este fondo escapa a toda lógica espacio temporal porque es eterno y en él todo se vacía hasta la nada; es, en definitiva, el fondo sin fondo, el fundamento vacío, el saber sin saber, la doble negación. Hay que entender este grund como un locus non locus «dado que la mediación (de Dios) se produce sobre el vacío del alma aniquilada, lo que a un tiempo anula toda mediación; en el orden de lo paradójico, se trata de un conocimiento cuyo modo carece de modo» (Vega, 2011: 23). Por tanto, el grund es un abgrund ${ }^{12}$ en el que la búsqueda de Dios tiene el modo de la negación de la negación, es decir, la nada de Dios. Esto no significa que el abgrund sea estéril, sino que, por el contrario, dado que en él ya no emergen imágenes de Dios, es la fuente originaria y sin porqué de la que nace la vida, privada de toda intención y voluntad humana y semejante a Dios en todos los atributos y modos.

Respecto del fondo del alma en Eckhart, Alois Haas (2002: 63) sostiene que:

línea correspondiente a la edición de 2011 de El fruto de la nada. En cada cita también mencionaremos la referencia exacta de la traducción de Ilse M. de Brugger.

12 Sobre esta temática, véase el estudio comparativo que hace Pektas (2006) entre Eckhart y Böhme. 
todas las metáforas del fondo del alma (...) son 'conceptos dinámicos de relación’ que no designan una parte del alma sino su relación dinámica más íntima con Dios, es decir, el afluir del torrente del ser del mismo Dios. Nunca se insistirá lo suficiente en este hecho si es que no se quiere malinterpretar como panteísmo la doctrina de Eckhart sobre el fondo del alma. En efecto, comprendida como análogon del intelecto increado de Dios.

Siguiendo el comentario que del sermón Vivir sin porqué desarrolla Amador Vega en la edición crítica El fruto de la nada de los sermones del Maestro Eckhart, «el fondo de Dios coincide con el fondo del alma y es el lugar en el que tiene lugar el nacimiento de Dios, el encuentro del Dios absolutamente separado de sí mismo y del alma igualmente anonadada (...). La aniquilación propia es el fundamento (grunt) sin fondo y es la base para la anulación divina (sacrificio)» (Eckhart, 2011: 251). A esta imagen del fundamento sin fondo, Eckhart también la llama «desierto» ${ }^{13}$, «fondo sin fondo» $\mathrm{O}$ «saber sin saber». Todas estas fórmulas tienen por objeto mostrar el absurdo de cualquier denominación de Dios, pues, siguiendo la tradición aeropagítica a la que se inscribe Eckhart, Dios no tiene más modos ni atributos que el de la nada. Como un eco de este postulado eckhartiano, para Heidegger en $\dot{\zeta}$ para qué poetas?, la época de la noche del mundo, en el que la divinidad ha desaparecido, es una penuria tan pobre que ni es capaz de ver lo que le falta. Con esta falta el mundo se priva del fundamento que funda. «Abismo significa originalmente el suelo y fundamento hacia el que, por estar más abajo algo se precipita. (...) entenderemos este «Ab» de la palabra abismo [Abgrunt] como la ausencia total del fundamento» (Heidegger, 2010: 242). El fundamento es, entonces, la superficie para la permanencia.

Como hemos visto, el abandono, el vaciamiento, el engendramiento de Dios en el alma y Dios como fondo sin fondo, entre otros, son temas eckhartianos de vital influencia y de evidente resonancia tanto en la obra de Angelus Silesius como en el pensamiento filosófico del s. $\mathrm{XX}^{14}$. Con el místico de Silesia el lenguaje llega a su máxima tensión, puesto que la potencia de las imágenes que utiliza contrasta con la impotencia de los conceptos, de tal suerte que es difícil identificar el horizonte que diferencie el sentido del sinsentido. Así, en la Introducción de El peregrino querúbico, un libro de excesos que «constituye una de las síntesis más sorpren-

13 Tanto en el tratado Del hombre noble (Eckhart, 2011: 153-165) como en la cuarta estrofa del poema Granum sinapsis (Eckhart, 2011: 183-186), Eckhart utiliza el desierto como una metáfora que simboliza al grunt como el locus non locus en el que desaparecen todas las determinaciones y modos de comprender a Dios según un algo.

14 Sobre la relación de la mística eckhastiana con la obra de Silesius y con el pensamiento filosófico del s. XX, véase: Haas (2009). 
dentes de la mística en uno de los periodos más convulsos de la historia europea» (Vega, 2011: 59), Lluís Duch (2005: 32) sostiene que ambos pensadores, Eckhart y Silesius, «no se cansan de afirmar que es necesario ir más allá de Dios, que la exigencia del que quiere que Dios nazca en su corazón ha de ser alcanzar el vacío». Para ello es necesario despojarse de las imágenes de Dios, ya que estas son precarias representaciones sicológicas del ser humano. Así, respecto al abandono, en los epigramas I, 22 y I, 44 Silesius (2005) afirma:

\section{El abandono}

Cuanto más te abandones a Dios, tanto más nacerá Él en ti.

Ni más ni menos te ayudará en tus sufrimientos.

Deben abandonarse a eso y aquello

Hombre, si amas alguna cosa, no amas verdaderamente.

Dios no es eso o aquello. Por eso mismo, ¡abandónalos!

Además de este desasimiento de cualquier intento de conocer a Dios por medio de imágenes creadas por el hombre, para Silesius es necesaria la virginidad del alma para que tenga lugar el nacimiento de Dios en ella, pues esta característica «comporta la negación sin restricciones de las atribuciones y de los puntos de partida concebidos como «absolutos», y que, por eso mismo, determinan negativamente la marcha y el progreso espirituales del ser humano» (Duch, 2005: 32-33). Por tanto, para Silesius, siguiendo a Eckhart y a Tauler, el hombre que ha dejado morir al yo personal para dar nacimiento al yo espiritual se hace semejante a Dios en atributos y lo ve como el verdadero Dios que es. En palabras del místico de Silesia:

I, 10

Yo soy como Dios, y Dios como yo

Soy tan grande como Dios. Él es tan pequeño como yo.

Él no puede estar sobre mí, ni yo debajo de Él.

I, 212

Yo como Dios, Dios como yo

Dios es lo que es. Yo lo que soy por mediación de Él.

Pero si conoces a uno de los dos, conoces a ambos.

I, 272

El hombre es imagen de Dios

Lo que Dios anhela y desea desde la eternidad.

Eso lo contempla en mí como su imagen.

En estos tres epigramas se evidencia uno de los temas eckhartianos de este camino hacia el interior del hombre, a través del cual también se 
conoce a Dios, a saber: la semejanza entre Dios y hombre. En el sermón Dios y yo somos uno, Eckhart sostiene que sólo es semejante a Dios quien es capaz de comprender la relación entre la justicia y lo justo, es decir, aquel que no tiene en absoluto voluntad y acepta lo que Dios quiere, sea o no para su provecho. En palabras del dominico en el tratado Pláticas instructivas:

que uno aprenda a desasirse de sí mismo hasta no retener ya nada propio. Todo el tumulto y la discordia provienen siembre de la propia voluntad, no importa que uno lo note o no. Uno mismo debe entregarse, junto con todo lo suyo, a la buena y queridísima voluntad de Dios, mediante el puro desasimiento del querer y apetecer, y esto con respecto a todo cuanto uno pueda querer o apetecer con miras a cualquier cosa (Eckhart, 1983: 141).

En últimas, es semejante a Dios todo hombre que es semejante a la nada, pues «nada es semejante al ser de Dios, en él no hay ni imagen ni forma» (Echkart, 2011: 79, 120). Es más, esta semejanza consiste en encontrar la unidad de Dios y hombre, de tal manera que el hombre, de un lado, por el conocimiento conciba a Dios en su interior y, de otro, por el amor penetre en él; esto es, que Dios no sea algo ajeno del hombre sino, en sí mismo, su propio bien. Esta dinámica de unicidad con Dios es expuesta por el Maestro Eckhart en el sermón Marta y María de la siguiente manera:

Fue esto lo que le sucedió a la querida Marta. Por eso (Cristo) le dijo: 'una cosa es necesaria', no dos. Yo y tú, una vez envueltos de la luz eterna, es uno y ese dos-uno es un espíritu ardiente, situado sobre todas las cosas y por debajo de Dios en el círculo de la eternidad. Aquél es dos, porque no ve a Dios sin mediación. Su conocimiento y su ser o también la imagen de su conocimiento jamás llegarán a ser uno. No ven a Dios, allí donde Dios es visto espiritualmente, libre de toda imagen. Uno llega a ser dos, dos es uno; luz y espíritu, esos dos son uno, envueltos de la luz eterna. (Eckhart, 2011: 143, 146-156)

Como otro eco del pensamiento de Eckhart en la filosofía del s. XX, sobre el dos-en-uno, Hannah Arendt, en La vida del espiritu, sostiene que en la unicidad del hombre se inserta la diferencia, la cual se muestra en el pensamiento debido a que este proceso «es una empresa solitaria pero no aislada; la solitud es aquella situación humana en la que me hago a mi mismo compañía. La soledad se presenta cuando estoy solo sin ser capaz de separar de mí los dos-en-uno, ni de hacerme compañía a mí mismo» (Arendt, 1984: 216). Es decir que en el pensar hay una dualidad de Yo conmigo mismo, haciendo de este una actividad verdadera puesto que 
soy yo quien pregunta y quien responde. Sólo de esta manera, sostiene Arendt (1984: 217), «el pensamiento puede llegar a ser dialéctico y crítico, porque pasa por este proceso de preguntas y respuestas».

Ahora bien, en lo que tiene que ver con el fundamento, Silesius (2005) mantiene que Dios es el fondo sin fondo puesto que «(Él) se fundamenta sin fundamento y se mide sin medida» (I, 42). Entonces, al igual que para Eckhart, para Silesius Dios es un abgrund que no cesa de entregarse y de invocar a su otro, es decir, al fondo del hombre que, a su vez, si está a la búsqueda de Dios, tampoco deja de llamar al fondo de Dios, pues el uno no puede ser sin el otro. Por esa razón, en la vocación los abismos no pueden distinguirse, de tal manera que la única palabra pronunciada se refiere al aniquilamiento, a la renuncia de todo. Como afirma Amador Vega:

en la descripción de este camino, que no es un lugar, se muestra el modo de comprensión de la divinidad, ella misma un lugar desocupado, sin fondo, en donde como un eco resuena la invocación patética del espíritu que, a su vez, yace en la oscuridad de su propio fondo: «el abismo de mi espíritu» invoca al abismo de Dios (Vega, 2011: 60).

Haciendo uso de la formulación de Salmos 42:8, las palabras Silesius (2005) al respecto son las siguientes:

I, 68

El abismo llama al abismo

A voces, el abismo de mi espíritu siempre invoca

$\mathrm{Al}$ abismo de Dios. Dime, ¿cuál es el más profundo?

En este dístico de Silesius no se puede distinguir quién llama a quien porque:

la dificultad con la que se encuentra nuestro discurso, que se esfuerza por distinguir entre los sujetos de esta vocación abismal, reside en nuestra ignorancia acerca de la topología de la mística, razón por la cual una aproximación a estos versos tendrá que contentarse con una descripción de aquellos lugares que el lenguaje señala como testigos silenciosos de los excesos verbales de los místicos (Vega, 2011: 61).

Por esta razón, aunque intentáramos analizar la naturaleza de esta vocación, nos encontraríamos, siguiendo a Martín Heidegger en el \56 de Ser y tiempo, dedicado al carácter vocativo de la conciencia, que «la conciencia habla única y constantemente en la modalidad del silencio» (Heidegger, 2009: 290), de tal manera que el llamado consiste en guardar 
el silencio sobre sí mismo, es decir, que la comprensión de la llamada radica en su usencia de fonación. Este silencio es para el místico, a diferencia que para el filósofo, motivo de atención, pues aquel siempre trata de escuchar la palabra del silencio.

Con todo, el tratamiento por parte de Eckhart y de Silesius de las categorías vistas anteriormente muestran el camino de preparación de todo hombre que, como el místico, pretenda unirse a Dios, en este caso por medio del conocimiento, aunque, como bien advierte Amador Vega:

la inteligencia es quien nos conduce; ahora bien, no sabemos adónde: el poeta empieza a comprender que quizá no importe si la cima es algo que haya que alcanzar antes o después, ni tan siquiera si es el final de trayecto, pues de pronto el camino se orienta hacia el desierto. No se trata tanto de lo que podríamos entender como un cambio de 'sentido', sino más bien del descubrimiento del camino interior (Vega, 2011: 46).

Dicho recorrido tiene como punto culminante el instante de coengredamiento de Dios en el hombre y del hombre en Dios, es decir: la unión mística. En otras palabras, el momento en el que el hombre alcanza la igualdad espiritual con Dios y cuando se hace tan rico, tan sabio y tan grande como Él, de tal manera que Dios no pueda hacer algo si no es con ese hombre, porque ambos son uno y el mismo en la dialéctica del dentro y del fuera. En el sermón titulado Marta y María, Eckhart nos muestra esta tensión ya no como la unión de dos en uno, sino como una figura para hablar de la verdad en tanto adequatio entre el interior y el exterior. En palabras del dominico: "Qué maravilla estar fuera como dentro, comprender o ser comprendido: ese es el final en el que el espíritu permanece en paz, en la unidad de la amada eternidad» (Eckhart, 2011: 145, 208-212). Así pues, caracterizada con la actitud de María, para quien Jesús es ante todo bondad, deseo inexpresable y dulce consuelo y felicidad; esto es, la mediación sin la cual no se puede llegar a Dios «obra y acción en la temporalidad y no empequeñece la salvación eterna» (Eckhart, 2011: 142, 122-123)-, este primer momento de reflexión de la mística especulativa, que supone el rechazo de lo exterior para enfocar la mirada hacia el interior del hombre, tiene una contrapartida, un segundo movimiento según el cual el espíritu, aislado de todo y unido a Dios, se niega nuevamente para retornar al mundo.

Marta, según Eckhart, es el modelo de dicho retorno porque para ella las cosas del mundo se perciben de manera distinta. Marta está junto a las cosas, no en las cosas; está junto al cuidado, no en el cuidado, de modo que en sus acciones cotidianas Dios se refleja porque entre ella y Dios ya no hay mediación alguna, sino que los dos son uno. Imitar a Marta, es 
decir, renunciar a la contemplación, prescindir de la mejor parte para obtener la mejor parte, es la tarea de todo aquel que se ha unido a Dios, y para quien la nada no se convierte en un ídolo más, sino que la niega tal como se negó a sí mismo. Se trata, en últimas, de ser un «liberado en vida»: «el que una vez superado el mundo fenoménico permanece en él en virtud de un acto de solidaridad cósmica con la materia» (Vega, 2006: 258).

\section{Anotaciones sobre una ética mística}

Las consecuencias que se pueden seguir del postulado anterior no son pocas. En el ámbito ético ${ }^{15}$, por ejemplo, se estaría hablando de una actitud según la cual la acción temporal sería tan noble como estar junto a Dios. Así, «con Eckhart se anula la diferencia entre las 'grandes' acciones virtuosas y las 'pequeñas' acciones no virtuosas. Todas las acciones del hombre, como acontecimientos puros, se conjugan ahora en una superficie dominante del sentido ético» (Flórez, 1983a: 89). Esto sería, tal como lo ha exigido Karl Rahner ${ }^{16}$ siguiendo a Eckhart, el esbozo de una mística de la vida cotidiana, en la que es necesario actuar con orden, inteligencia y prudencia. Al respecto el maestro dice: «llamo con orden a lo que en todos los lugares corresponde a lo sublime; con inteligencia al no conocer nada mejor en el tiempo; y con prudencia cuando en las obras buenas se encuentra la verdad viva con su presencia benefactora» (Eckhart, 2011: 145, 27-31). En otras palabras, la concepción ética que de aquí se sigue consiste en actuar sin obstáculos, es decir, sin porqués. La formulación sin porqué, de un lado, es el eje del sermón eckhartiano Vivir sin porqué, en el que el místico renano sostiene: «quien durante mil años preguntara a la vida: “¿por qué vives?”, si pudiera responder no diría otra cosa que «vivo porque vivo». Eso es así porque la vida vive de su propio fondo y brota de lo suyo; por eso vive sin porqué, porque vive de sí misma» (Eckhart, 2011: 72, 102-106; 1983: 308); de otro lado, el sin

\footnotetext{
15 La ética de Eckhart es una ética de la negación, en la que la única norma universal es Dios y su amorosa voluntad. Por esta razón, «el hombre deberá negar, en todos los aspectos de su vida, todo aquello que no sea Dios; primera y fundamentalmente deberá negarse a sí mismo» (Flórez, 1983a: 90). Con todo, de un lado es claro que el sujeto de la ética eckhartiana es el hombre que, si bien pareciera tener dominio absoluto de sus emociones y afecciones, no es un arquetipo sino un hombre alcanzable a cualquiera. De otro, el objeto de esta ética es la unión con Dios, que se basa en la negación que permite al hombre liberarse de todo aquello que no sea Dios. Para un desarrollo más profundo de la ética de Eckhart, véase: Flórez (1983b).

16 Sobre esta exigencia del teólogo alemán, véase: Rahner (1978: 210, 235, 241, 243, $245,248)$.
} 
porqué es expuesto en uno de los epigramas más conocidos de Angelus Silesius (2005) del siguiente modo:

\section{I, 289}

Sin porqué

La rosa es sin porqué. Florece porque florece.

A ella misma, no presta atención. No pregunta si se la mira.

En el análisis que Heidegger hace de esta frase, nos dice Amador Vega (2011: 75), «la mística y la poesía de estas palabras de Silesius han atravesado ya los modos de pensamiento». A primera vista la formulación de la primera parte del alejandrino del místico de Silesia parece ser contradictoria, pero si se analiza proposición a proposición, la inicial - «La rosa es sin porqué»- no se contradice con la final - «florece porque florece»— en la medida en que aquella se refiere a la búsqueda, y ésta, a la aportación. En palabras de Heidegger (1991: 73): “"porqué” y "porque" significan cosas diferentes. Porqué es la palabra para la búsqueda por el fundamento. El porque contiene un apuntar, un apuntar que responde, dirigido al fundamento. El porqué busca el fundamento. El porque lo aporta». Así, en la medida en que la parte inicial del primer verso del epigrama rechaza que haya algún fundamento, la segunda lo afirma rotundamente. Entonces, el verso nos muestra «una simultánea afirmación y negación de lo mismo, a saber del fundamento» (Heidegger, 1991: 73).

Ahora bien, desde la perspectiva heideggeriana, para comprender el fundamento buscado por la primera parte del verso y el aportado por la segunda, es necesario pasar a la segunda sentencia del epigrama. Analizándolo en sus dos proposiciones, la primera deja ver el papel de la preposición sin de la primera parte del primer verso, según la cual a la rosa no le es necesario tener un cuidado de sí porque en su modo de ser no necesita cuidarse de todo aquello que la determina. Esto no quiere decir que la rosa no tenga ningún fundamento, sino que existe en cuanto florece sin atender a todo aquello que, al ser algo diferente a ella, podría realizar tal cosa (Heidegger, 1991: 74). Conociendo los postulados heideggerianos sobre la preposición tratada, Jacques Derrida afirma, desde el primer capítulo «Pas» de su obra Parages (1986), que el sin no es una preposición que necesariamente represente carencia, o que contraponga dos cláusulas gramaticales; es más:

El sin no disocia solamente la atribución singular de la generalidad esencial: la sabiduría como ser-sabio en general, la bondad como el ser-bueno en general, la potencia como ser-potente en general. No evita sólo la abstracción ligada a todo nombre común y al ser implicado en toda generalidad esen- 
cial: transmuta también en afirmación, en la misma palabra y en la misma sintaxis, su negatividad puramente fenomenal, aquella que el lenguaje ordinario, clavado a la finitud, da a entender en una palabra como sin o en otras análogas. Desconstruye el antropomorfismo gramatical (Derrida, 2011a: 18).

Es decir que el sin no sólo evita la abstracción de la esencia de todo nombre común, sino que transforma cada palabra, dentro de su uso sintáctico, en afirmación, superando el límite negativo puramente fenomenal de la preposición. Por tanto, el sin no indica necesariamente negatividad, menos aún aniquilación, por el contrario, dice Derrida (2002: 292), «si esta preposición efectúa cierta abstracción, es para tomar también en consideración los efectos necesarios de la abstracción, de la abstracción del hay, de la abstracción que hay» (Derrida, 2002: 292). Ahora bien, si forzamos un poco la interpretación del filósofo argelino, podríamos hacer un juego derridiano acerca del sin, pues dado que en francés la pronunciación de la preposición sin (sans/sã/) puede ser confundida con la de la palabra sentido (sens / sãs/), si aguzamos el oído podríamos escuchar el momento afirmativo del sans unido al sens, que más allá de ser sin sentido, es el sens sens, el sentido sentido, el fondo fondo, la pura positividad.

Ahora bien, volviendo el análisis de Heidegger sobre la segunda parte del verso final del epigrama de Silesius, se toma como centro al hombre, quien, según el filósofo alemán, se diferencia de la rosa porque éste mantiene su mirada en el mundo, pues «no podemos ser los seres que somos sin prestar atención al mundo que nos determina; una atención en la cual, al mismo tiempo, atendemos a nosotros mismo» (Heidegger, 1991: 74). Sin embargo, lo anterior no quiere decir que el hombre sea diferente a la rosa, sino que, «en el fondo más oculto de su esencia, no es de verdad más que si a su modo es, como la rosa, sin porqué» (Heidegger, 1991: 75).

\section{A modo de gozne conclusivo}

La tematización religiosa del hombre abordada en el primer apartado de este artículo nos ha permitido peregrinar por conceptos como los de promesa, ausencia, modus loquendi, abandono, vaciamiento, coengendramiento, abismo, entre otros, los cuales aluden a la relación del hombre con Dios. Ahora, para finalizar esta presentación, expondremos brevemente una de las tensiones propias de la mística renana, a saber: la concerniente al dentro y al afuera. Dicha tensión la podemos ilustrar, desde Eckhart, de dos maneras: una, como un camino sin camino; otra, como un gozne de puerta. 
En cuanto a la primera imagen, aún teniendo en cuenta que para Haas el Maestro Eckhart se distancia de cualquier posibilidad de una teología del camino (Vega, 2011: 82), traemos a colación las palabras del dominico en el sermón Marta y María, en el que muestra los tres caminos que tiene el alma para conducirse hacia Dios. El primer camino es el franciscano, en el que se busca a Dios por medio de una acción múltiple, es decir, con amor ardiente en todas las criaturas. El segundo «es el arrobamiento en la visión sin velos que, al tener lugar in statu via, no puede poseer estabilidad alguna pero que, no obstante, prefigura el statu gloricas (Haas, 2002: 109); se trata, de un camino sin camino, «libre y sin embargo atado, en donde se es elevado y arrebatado sin voluntad y sin imagen sobre sí mismo y todas las cosas, aunque no sea permanente en su esencia» (Eckhart, 2011: 143, 163-166). El tercero, más allá de la aparente paradoja que esta senda hacia Dios pueda acarrear, deviene en un «estar en casa», en la contemplación de Dios sin mediación alguna. Y dado que Cristo dice «Yo soy el camino, la verdad y la vida» (Jn 14, 6), fuera de estos tres caminos el hombre busca rodeos y mediaciones. «Ser conducido a Dios en esos caminos por la luz de su Verbo y envuelto por el amor del Espíritu (Santo) está más allá de lo que puede ser expresado en palabras» (Haas, 2002: 110).

Desde estas sendas Eckhart nos conduce a la segunda imagen por medio de las siguientes palabras: «Qué maravilla estar fuera como dentro, comprender o ser comprendido, ver y al mismo tiempo ser visto, contener y ser contenido: ése es el final en el que el espíritu permanece en paz, en la unidad de la amada eternidad» (Eckhart, 2011: 145, 208-211). Por tanto, en lo concerniente al gozne de puerta, la dinámica del hombre religioso consiste en, como sostiene el místico renano en el tratado $\mathrm{Del}$ ser separado, una puerta que abre y se cierra en un gozne. "Ahora yo comparto la plancha exterior de la puerta con el hombre exterior; el gozne, sin embargo, lo tengo por igual al hombre interior. Cuando la puerta se abre y cierra, entonces se mueve la plancha exterior de aquí para allá y, con todo, el gozne permanece inmóvil en su lugar» (Eckhart, 2011: 175, 287-193; 1983: 248).

La dinámica de salida y entrada es una clara referencia al proceso de desasimiento espiritual, que se ha de entender como las acciones realizadas a un mismo tiempo, puesto que para aquel que ha conseguido el abandono su salir se convierte en un entrar. Tal como lo manifiesta Silesius (2005) en el primer verso de su dístico V, 14: «No hay salida que no sea a causa de la entrada». Por tanto, este proceso es doble porque primero se trata de un salir del yo creatural que está en el mundo para entrar en el yo espiritual; y después, de un salir de ese yo espiritual, pero sin 
abandonarlo, para entrar nuevamente en el yo creatural, que no es el mismo de antes porque ahora está junto al mundo.

Con todo, el camino sin camino de estas páginas, en el sentido positivo de la preposición, intenta esbozar uno de los objetivos eckhartianos presente en sus Conversaciones formativas: «hallar una vía mixta entre vita activa y vita contemplativa» (Vega, 2011: 19). En otras palabras, se trata de un vivir y actuar en el mundo como si no se estuviera en el mundo, esto es, en un actuar según los modos sin modos de Dios, porque el ser humano es «un espacio de tránsito; (...) el vacío necesario para toda creación» (Vega, 2006: 248).

\section{REFERENCIAS}

-Arendt, H. (1984). La vida del espiritu. El pensar, la voluntad y el juicio en la filosofía y en la política (R. Montoro Romero \& F. Vallespin Oña, Trads.). Madrid: Centro de estudios constitucionales.

-De Amberes, H. (2005). Visiones. (M. Tabuyo, Trad. y Ed.) Palma de Mallorca: Editorial José J. de Olañeta.

-De Amberes, H. (2013). El lenguaje del deseo. (M. Tabuyo, Trad.) Madrid: Editorial Trotta.

-De Certeau, M. (2006a). La debilidad de creer. (V. Goldstein, Trad.) Buenos Aires: Katz Editores.

-De Certeau, M. (2006b). La fábula mística (siglos XVI-XVII). (L. Collel Aparicio, Trad.).Madrid: Ediciones Siruela.

-Derrida, J. (1986). Parages. Paris: Éditions Galilée.

-Derrida, J. (2002). Marx e hijos. En M. Sprinker (Ed.), Demarcaciones espectrales (M. Malo de Molina, A. Riesco Sanz \& R. Sánchez Cedillo, Trads., págs. 247-306) Madrid: Akal.

-Derrida, J. (2011a). Como no hablar: Y otros textos. (P. Peñalver Trad.) Barcelona: Anthropos Editorial.

-Derrida, J. (2011b). El tiempo de una tesis. Deconstrucción e implicaciones conceptuales. (P. Peñalver, Trads.) Barcelona: Anthropos Editorial.

-Duch, L. (2005). Introducción. El peregrino querúbico. Madrid: Ediciones Siruela.

-Duch, L. (2011). Presentación del libro Tres poetas del exceso. La hermenéutica imposible en Eckhart, Silesius y Celan, de Amador Vega. Barcelona: Librería La Central. Recuperado de http:/ / www.youtube.com/watch?v=WhHYxNsx6gw\#t=256.

-Eckhart. (1983). Tratados y sermones. Obras alemanas (I. M. de Brugger, Trad.). Barcelona: Edhasa.

-Eckhart (2011). El fruto de la nada (A. Vega, Trad. y Ed.). Madrid: Alianza Editorial/Ediciones Siruela.

-Flórez Flórez, A. (1983a). Eckhart y la ética. Universitas Philosophica, 1(1), 89-97.

-Flórez Flórez, A. (1983b). La ética de Meister Eckhart. Bogotá: Pontificia Universidad Javeriana. 
-Freud, S. (2003). Duelo y melancolía. En J. Numhauser Tognola (Ed.), Obras Completas (L. López-Ballesteros, Trad., pp. 2091-2100). Madrid: Biblioteca Nueva.

-Haas, A.M. (1999). Visión en azul. Estudios de mística europea (V. Cirlot \& A. Vega, Trads.). Madrid: Ediciones Siruela.

-Haas, A.M. (2002). Maestro Eckhart. Figura normativa para la vida espiritual (R.H. Bernet, Trad.). Barcelona: Editorial Herder.

-Haas, A.M. (2007). ¿Por qué y para qué estudiamos la mística? Philía. Revista de la Bibliotheca Mystica et Philosophica Alois M. Haas, 1, 9-49.

-Haas, A.M. (2009). Viento de lo absoluto. ¿Existe una sabiduría mística de la posmodernidad? (J. Seca, Trad.). Madrid: Ediciones Siruela.

-Heidegger, M. (1991). La proposición sin fundamento (F. Duque \& J. Pérez de Tudela, Trads.). Barcelona: Serbal.

-Heidegger, M. (2009). Ser y tiempo (J. E. Rivera, Trad.). Madrid: Editorial Trotta. -Heidegger, M. (2010). Caminos de bosque (Segunda edición) (H. Cortés \& A. Leyte, Trads.). Madrid: Alianza Editorial.

-Hulin, M. (2007). La mística salvaje (M. Tabuyo \& A. López, Trad.). Madrid: Ediciones Siruela.

-Lonergan, B. (1999). Insight. Estudio sobre la comprensión bumana (F. Quijano, Trad.). Salamanca/México DF: Sígueme/Universidad Iberoamericana de México.

-Lonergan, B. (2006). Método en teología (Cuarta edición). (G. Remolina, Trad.). Salamanca: Sígueme.

-McGinn, B. (1989). Love, Knowledge and Unio Mystica in the Western Christian Tradition. En M. Idel \& B. McGinn (Eds.), Mystical Union and Monotheistic Faith. An Ecumenical Dialogue (pp. 59-86). New York/London: Macnillan Publishing Company/Collier Macmillan Publishers.

-Nava Murcia, R. (2011). Michel de Certeau y la escritura de la historia: hacia una erótica del duelo. Fractal revista trimestral, 63, 35-52.

-Pektas, V. (2006). Mystique et Philosophie. Grunt, abgrunt et Ungrund chez Maître Eckhart et Jacob Böhme. Amsterdam/Philadelphia: B.R. Grüner.

-Porete, M. (2008). El espejo de las almas simples (B. Garí, Trad.). Madrid: Ediciones Siruela.

-Rahner, K. (1978). Rahner, Schriften zur Theologie (Vol. 13). Einsiedeln: Benziger.

-Schopenhauer, A. (2010). El mundo como voluntad y representación (Vol. 2; R. Aramayo, Trad.). Madrid: Alianza Editorial.

-Silesius, A. (2005). El peregrino querúbico (L. Duch, Trad.). Madrid: Ediciones Siruela.

-Vega, A. (2006). Antoni Tàpies: "Negatio negationis". Un espacio de meditación y silencio. En A. Vega, \& V. Cirlot, (Eds.), Mistica y creación en el siglo XX (pp. 241-266). Barcelona: Herder Editorial.

-Vega, A. (2011). Tres poetas del exceso. La hermenéutica imposible en Eckhart, Silesius y Celan. Barcelona: Fragmenta editorial.

-Von Magdeburg, M. (2004). La luz divina que ilumina los corazones (P. D. Gutiérrez, Trad.). Burgos: Monte Carmelo. 
-Wittgenstein, L. (1999). Tractatus Logico-Philosophicus (J. Muñoz \& I. Reguera, Trad.). Madrid: Alianza Editorial.

Sumario: Introducción. 1. Consideraciones preliminares; 2. Camino sin camino. Del doble movimiento de Eckhart y Silesius hacia el pensamiento filosófico del s. XX; 3. Anotaciones sobre una ética mística; 4. A modo de gozne conclusivo; Referencias. 